\title{
DE CLERAMBAULT SYNDROME: A CASE REPORT
}

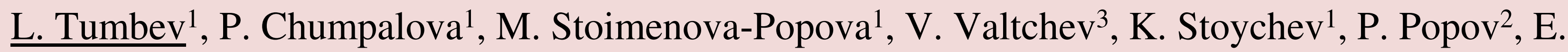
Krasteva ${ }^{4}$

${ }^{1}$ Medical University, Psychiatry and Medical Psychology, Pleven, Bulgaria.

${ }^{2}$ Ministry of Health, National Center for Addictions, Sofia, Bulgaria.

${ }^{3}$ National Sports Academy, Department of Biochemistry and Physiology, Sofia, Bulgaria

${ }^{4}$ UMHAT "Dr. Georgi Stranski", Mental Health Center, Pleven, Bulgaria

Key words: De Clerambault syndrome, man

Objectives: To present a case of man with Bipolar Affective Disorders and De Clerambault syndrome.

Background: De Clerambault, a French psychiatrist, described in 1921 a syndrome he termed "psychose passionelle." This syndrome generally occurs in women, although it has occasionally been reported in men.

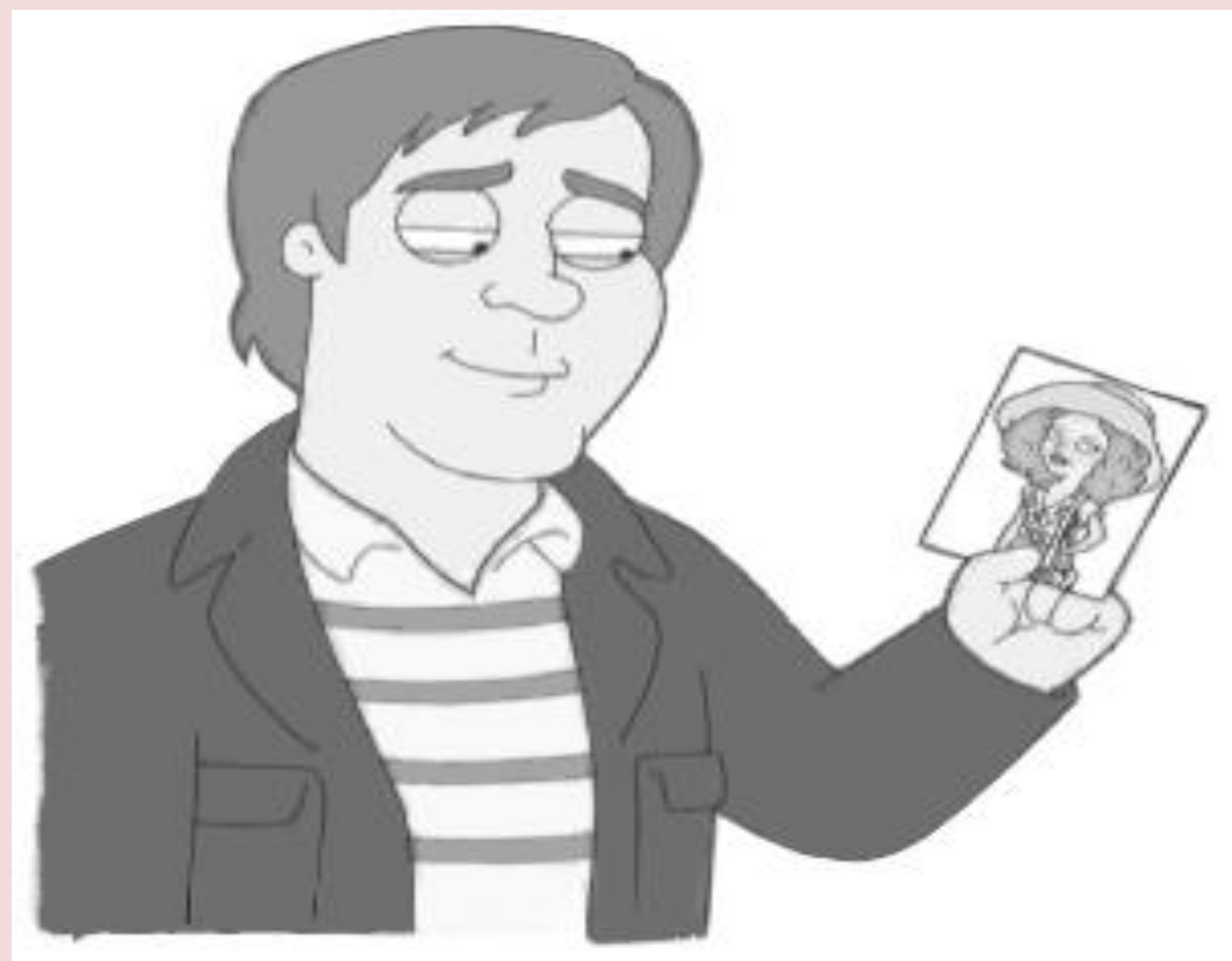

Materials and Methods: A 58-year-old man with diagnosed with a Bipolar Affective Disorders of 18 years. For about 10 years, he has been in love with a psychiatrist who is not involved with his treatment, sends her letters, sends gifts. He says that will make the perfect home for her, because this is her wish to live together.

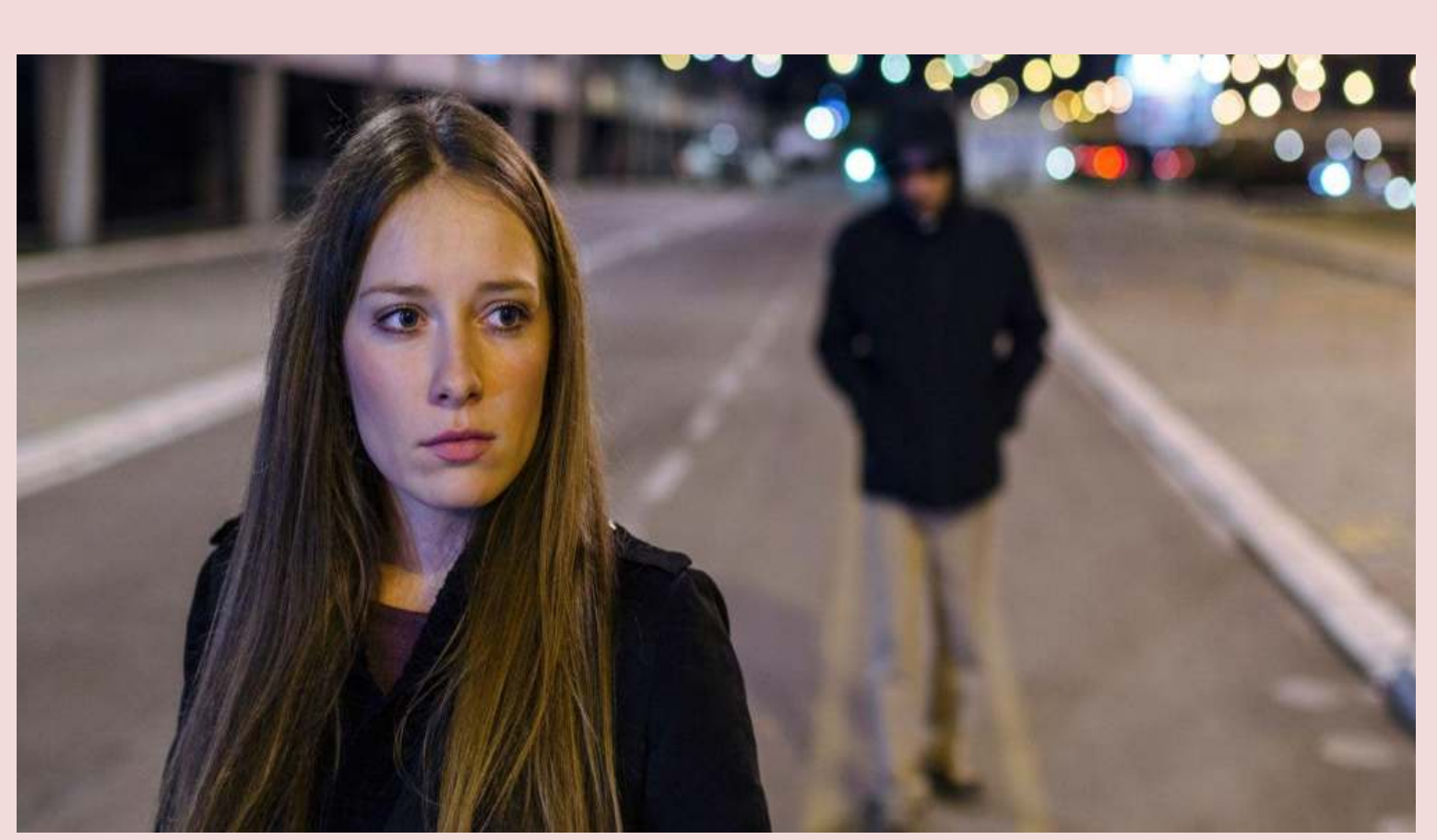

He writes how well she will live together. Over the past two years psychiatrist married, he began to sending letters threatening to kill her husband. During a manic episode significantly increased attempts to contact the object of his love. During the years of the disease, the patient was treated with various combinations of antidepressants, moodstabilizeters and antipsychotics.

Results and Conclusions: 2 years ago, after the threat of killing a spouse of the psychiatrist who loves him and wants to live with him, the patient is placed in forced treatment. Treated with Ziprasidone $60 \mathrm{mg}$ daily. 6 months after the discharge, the patient is fine and regrets that he has bothered the psychiatrist. De Clerambault syndrome is difficult to diagnose and treat. Disturbs the life of both the patient and the subject of love. 